\title{
Optimization of in vitro rooting protocol for tomato (Lycopersicon esculentum mill.) varieties
}

\author{
Endalkachew Baye* \\ Department of Plant Sciences, College of Agriculture and Natural Resource, Salale University, \\ P.O BOX 245, Fitch, Ethiopia \\ Temesgen Matewos \\ Department of Horticulture and Plant Sciences, Jimma University, P.O BOX 138, Jimma, \\ Ethiopia

\section{Derbew Belew} \\ Department of Horticulture and Plant Sciences, Jimma University, P.O BOX 138, Jimma, \\ Ethiopia
}

${ }^{*}$ Corresponding author. Email: bayeendalkachew4@gmail.com

\section{Article Info}

https://doi.org/10.31018/

jans.v12i3.2223

Received: February 22, 2020

Revised: July 28, 2020

Accepted: August 16, 2020

\section{How to Cite}

Baye, E. et al. (2020). Optimization of in vitro rooting protocol for tomato (Lycopersicon esculentum mill.) varieties. Journal of Applied and Natural Science, 12(3): 365 - 371.https://doi.org/10.31018/jans.v12i3.2223

\begin{abstract}
In vitro rooting of micropropagated shoots were carried out with the aim of evaluating the root induction responses of two tomatoes (Lycopersicon esculentum MILL) varieties (Gelilema and Chali) using Indole -3- butyric acid (IBA). Seven levels of IBA $\left(0.0,0.25,0.5,0.75,1.0,1.25\right.$ and $\left.1.5 \mathrm{mg} \mathrm{L}^{-1}\right)$ were used in a completely randomized design (CRD) in factorial combinations (seven level of IBA*two varieties) with three replications. After the plantlets were kept in the rooting media for three weeks, data on rooting percentage, number of roots/shoots and root length in $\mathrm{cm}$ were collected. The analysis of variance showed that the interaction of IBA* Var was highly significantly different for rooting percentage, a number of roots/shoot and root length at $p<0.01$. The highest rooting percentage $(100.00 \pm 0.00)$, number of roots/shoot $(14.20 \pm 0.35)$ and root length $(10.7 \pm 0.29)$ were received from Chali on free Murashige and Skoog medium (MS). At the same time, the lowest percentage of rooting $(11.11 \pm 0.00)$, number of roots/shoot $(0.887 \pm 0.19)$ and root length $(1.00 \pm 0.00 \mathrm{~cm})$ were obtained from Gelilema on $\mathrm{MS}+1.5 \mathrm{mg} / \mathrm{l}$ IBA. For acclimatization, the in vitro rooted shoots were transplanted into plastic pots containing a mixture of oven sterilized soil and sand at a ratio of 2:1. After three weeks, a survival rate of $67.7 \%$ for Chali and $58.1 \%$ for Gelilema was obtained. From the above result, it can be concluded that free MS medium was the best for in vitro rooting of the two tomato varieties. The optimized protocol will be useful for rapid in vitro multiplication of the two tomato varieties.
\end{abstract}

Keywords: Chali, Gelilema, IBA, In vitro rooting, Tomato

\section{INTRODUCTION}

Tomato (Lycopersicon esculentum Mill.) is one of the most important vegetables in the world. It is a dicotyledonous plant that belongs to the family of Solanaceae and genus Lycopersicon (Kalloo, 1991). It is a diploid with $2 n=2 x=24$ chromosome. Nowadays, it grows almost in every country of the world either in the field, greenhouses or net houses (Jehan and Hassanein, 2013). The five leading tomato producing countries in the world are China, India, United States, Turkey and Egypt. The total area under tomato cultivation in the world, Africa and Ethiopia is about, $4.78 \mathrm{mln}$ ha, $1.27 \mathrm{mln}$ ha and 6299 ha with an average yield of
37.09, 15.59 and 4.5 ton/ha respectively (FAO STAT, 2016). In Ethiopia, tomato has been cultivated for economic importances like a source of income, creating employment opportunity and access to farmers to participate in the market (Eyob et al., 2014). It also used as a sample for the study of genomics, proteomics and metabolomics (Jehan and Hassanein, 2013). Even if tomato has numerous benefits, its production is not equivalent to its area of coverage. This is due to the influence of several biotic and abiotic factors like diseases, pests, environmental stress, post-harvest losses and propagation method (Mukta, 2014; Datta, 2015). The use of a hybrid variety is a great option to increase yield for most of the vegetable crops, includ- 
ing tomato. But the mentioned factors also cause the decline of hybrid seed recovery from the field. Tomato is one of the vegetable crops which have been grown from hybrid seeds that are obtained by crossing two or more genetically different parents in every cropping season (Gao, 2017). Hybrid tomato varieties continue to dominate high input agricultural systems. This increase in demand for hybrid seeds stresses commercial hybrid seed production abilities. Because most of the hybrid seeds of tomatoes are produced by hand emasculation, hand pollination and hybridization, which are labour-intensive (Cheema and Dhaliwal, 2005; Sudha et al., 2006). Additionally, seeds saved after $\mathrm{F} 1$ hybrids produce plants that are inferior and not uniform because, seeds do not remain genetically true to type (Opeña et al., 2001a). Such the improvement of a plant through conventional breeding method is slow, time-consuming and need more space (Moghaieb et al., 1999).

Plant tissue culture is one of the important tools of biotechnology, which has been used for increasing the productivity of a given crop by supplying improved planting materials within a short period of time and a limited space (Mohamed et al., 2010). In tomato, it has been used for selection of cell lines for biotic and abiotic stresses (Rahman and Kaul, 1989), development of haploids (Shtereva et al., 1998), production of somatic hybrids (Wijbrandi et al., 1988), mass propagation (Izadpanah and Khosh-Khui, 1992) and development of transgenic tomato (Kiran, 2007).

Different plant growth regulators (PGRs) have been used by different researchers for tomato in vitro rooting. According to Bahurupe et al. (2013), tomatoes do not require any exogenous growth regulators for root induction. Similarly, Ashakiran et al. (2011) found that MS medium devoid of exogenous auxin produced adventitious roots in two tomato varieties. However, Mamidala and Nanna (2011) reported that root formation of tomatoes had been achieved with auxin (Indole-3-Acetic Acid (IAA), Naphthalene Acetic Acid (NAA) or Indole-3 Butyric Acid (IBA) alone with a concentration of $0.1-1 \mathrm{mg} / \mathrm{l}$. The establishment of one universal protocol for in vitro rooting of all the varieties is impossible (Gerszberg et al., 2015). Because morphogenic responses of cultured tomato plant tissues are affected by the genotype and explant (size, age and orientation) (Bhatia, 2003). Therefore, this research work was initiated with the objective to find out the optimum concentration of IBA for root formation of two tomato varieties (Gelilema and Chali) of L. esculentum.

\section{MATERIALS AND METHODS}

Two-hybrid tomato ( $L$. esculentum) varieties named Chali and Gelilema were used as an experimental ma- terial, which was obtained from Melkassa Agricultural Research Center (MARC). The varieties were selected based on their best performances. They are the newly introduced, and being widely distributed varieties to farmers.

Murashige and Skoog (MS) media supplemented with various plant growth regulators were used. Stock solutions of the macro salts, micro salts, vitamins, iron source and plant growth regulators $(1 \mathrm{mg}: 1 \mathrm{ml})$ were prepared and stored at $4^{\circ} \mathrm{C}$ in the refrigerator. Plant growth regulator, auxin (IBA) were dissolved using a drop of ethanol before making up the final volume with distilled water. Iron EDTA (Ethylene Di Amine Tetra Acetic Acid) stock solution was covered with aluminum foil. Culture medium was prepared from all stock solutions (macro, micro, iron and vitamins). The medium was solidified with $0.8 \%(\mathrm{w} / \mathrm{v})$ agar and $3 \%$ sucrose was added as an energy supply. The $\mathrm{pH}$ was adjusted to 5.8 using $1 \mathrm{~N} \mathrm{NaOH}$ or $\mathrm{HCl}$ prior to the addition of agar. Growth regulators were added according to the concentration required. Then $50 \mathrm{ml}$ media were dispensed into washed and sterilized culture jars, then plugged and labelled properly. Then the medium was steam sterilized using an autoclave chamber at a temperature of $121^{\circ} \mathrm{C}$ and a pressure of $105 \mathrm{KPa}$ for 15 min. Finally, the autoclaved media were taken out of the autoclaving chamber and put on the shelf for 4 days until used.

After the prepared culture media stayed for 4 days, the in vitro grown shoots that had $\sim 3 \mathrm{~cm}$ length were excised and cultured on free MS medium for two weeks to avoid the carryover effect. Then, the shoots were transferred on MS medium supplemented with IBA at $0.0,0.25,0.5,0.75,1.0,1.25$ and $1.5 \mathrm{mg} / \mathrm{l}$. The experiment was laid out using CRD in factorial combinations (seven levels of IBA*two varieties) with three replications. Three shoots/jar were used. After the plantlets were kept in the rooting media for three weeks, data on rooting percentage, number of roots/shoots and root length in $\mathrm{cm}$ were collected (Namitha and Negi, 2013, Sherkar and Chavan, 2014). For the collected data analysis of variance (ANOVA) was performed using SAS software Packages (version 9.3). A least significant difference (LSD) was used for the comparison of significant differences between means at $\mathrm{P}<0.01$.

\section{RESULTS AND DISCUSSION}

The ANOVA obtained from rooting experiment indicated that the interaction effect of variety and IBA were highly significant for rooting percentage, the number of roots/explant and root length of the two tomato varieties at $\mathrm{P}<0.01$.

The highest rooting percentage $(100.00 \pm 0.00)$ was obtained from an IBA level ranging from $0.0-0.75 \mathrm{mg} / \mathrm{l}$ 
IBA in both of the varieties of tomato ( $L$. esculentum) used for the experiment (Table 1; Figure 1). Whereas, the lowest percentage of rooting $(11 \pm 0.00)$ were obtained from Gelilema variety grown on MS medium supplied with $1.5 \mathrm{mg} / \mathrm{IBA}$ while for Chali the lowest rooting percentage was $(55.6 \pm 19.25)$ which was from the same level of IBA as Gelilema's lowest. This result indicates that each genotype responded differently, which may be due to differences in their endogenous auxin amount. A similar result was reported by Singh et al. (2006) who reported that different genotypes require different concentrations of auxin and their response is dependent on the amount of their endogenous auxin concentration for sugarcane varieties. Similar to our rooting percentage, Osman et al. (2009) found $100 \%$ rooting in both full and half-strength MS medium without growth regulators over different levels of NAA, IAA, or IBA for in vitro rooting of Omdurman tomato cultivar.

The increase in the concentration of IBA from $0 \mathrm{mg} / \mathrm{l}$ to $1.5 \mathrm{mg} / \mathrm{l}$ resulted in the decrease of rooting percentage. This is similar with the finding of Sakthivel and Manigandan (2011) who suggested that better rooting parameters were obtained from a media supplied with low level of IBA. In their experiment, they obtained $100 \%$ rooting in $0.5 \mathrm{mg} / \mathrm{IIBA}$ and $0.00 \%$ rooting at 2 $\mathrm{mg} / \mathrm{l} \mathrm{IBA}$. The root length was also better in lower IBA levels. In another rooting experiment, Ishag et al. (2009) reported the same result. They recorded 100\% rooting in MS medium without IBA. Low concentration of IBA promotes root induction and elongation than higher concentration that inhibited rooting in both varieties. However, Bhatia (2003) reported that tomato rooting response was dependent on the auxin type used. The author said that tomato cultivar Red Coat response increased with an increase in IAA concentration whereas, with NAA, the response decreased as the concentrations increased. Pampanna (2009) reported a contradictory result to the present work. In an experiment conducted using cotyledon and hypocotyl explants derived from tomato cultivar VYBHAV, the researcher found that the rooting percentage of both explants increased as the concentration of IBA increased from the control to $1.5 \mathrm{mg} / \mathrm{l}$. From MS medium free of IBA the author found 29 and $35 \%$ rooting respectively while at $1 \mathrm{mg} / \mathrm{IIBA} 96$ and $98 \%$ rooting was reported. This may also be due to the dependence of plants on the level of their endogenous auxin to give response for exogenous auxin. In another research, Sherkar and Chavan (2014) obtained 100\% rooting on MS medium augmented with IBA concentrations ranging from control-3 $\mathrm{mg} / \mathrm{l}$.

During rooting of the tomato varieties used as an experimental material, there is no significant difference in rooting percentage in IBA levels 0-0.75 $\mathrm{mg} / \mathrm{l}$ (Table 1). Mensuali-Sodi et al. (1995) and Devi et al. (2008) also reported the presence of exogenous auxin enables tomato to give roots without requiring

Table 1. Effect of IBA on $n$ vitro rooting of tomato varieties (Gelilema and Chali).

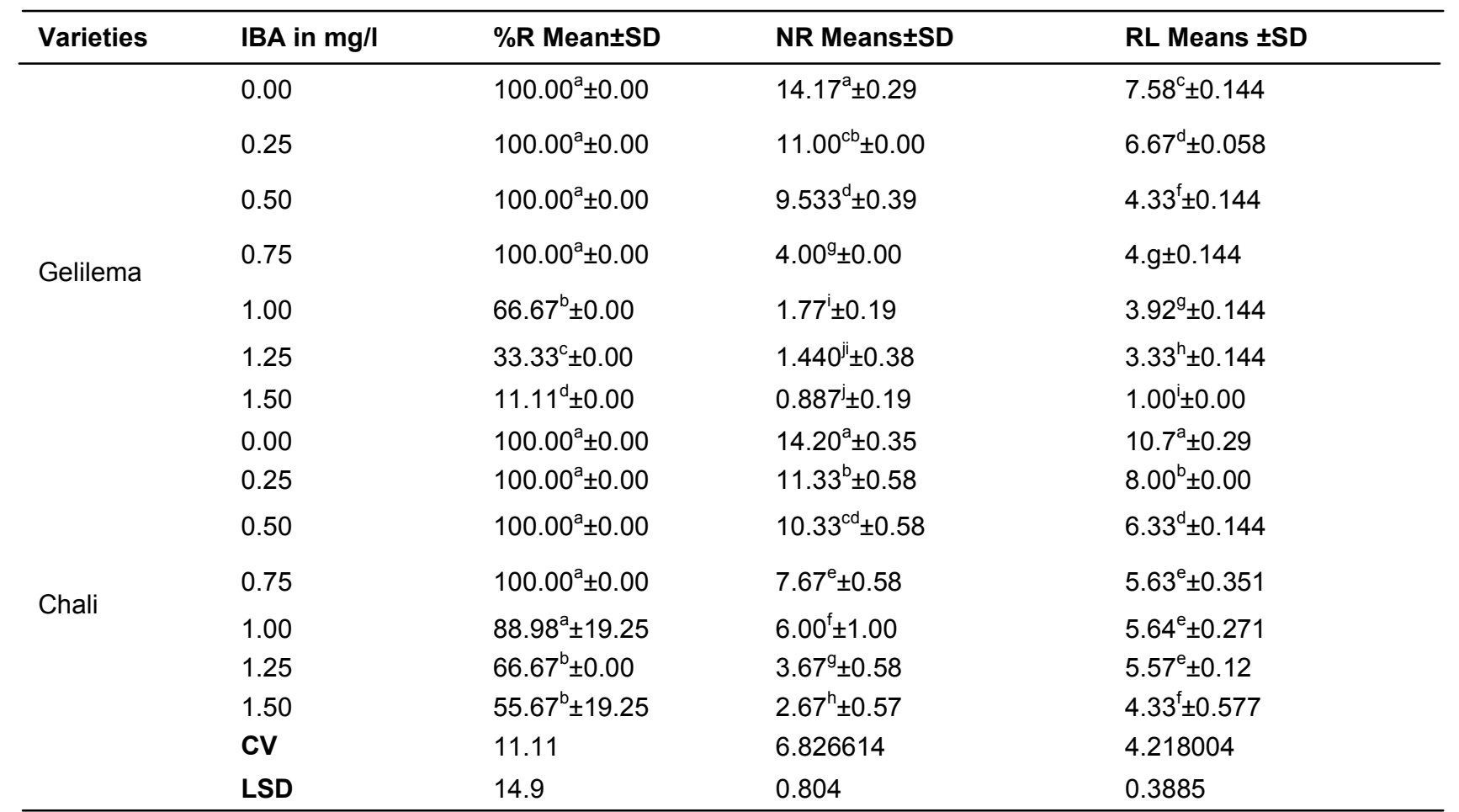

Note: Values are given as Mean $\pm \mathrm{SD}$. Means with different letters within the same column (s) are significantly different from each other at $\mathrm{P} \leq 0.01$. Where: $\% \mathrm{R}=$ rooting percentage, $\mathrm{NR}=$ average number of roots and $\mathrm{RL}=$ average root length in $\mathrm{cm}$. 

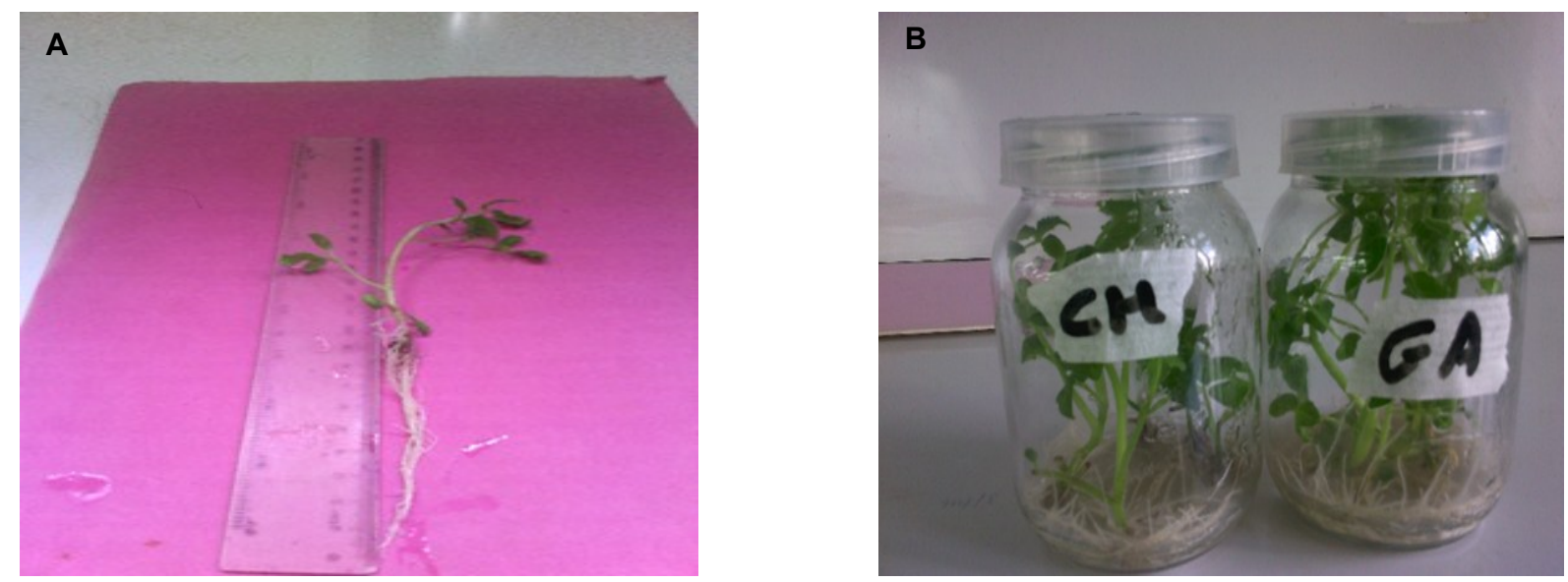

Fig. 1. In vitro rooting of Two Tomato varieties (A. Root length measurement, B. Chali and Gelilema Varieties of Tomato on IBA free MS medium).
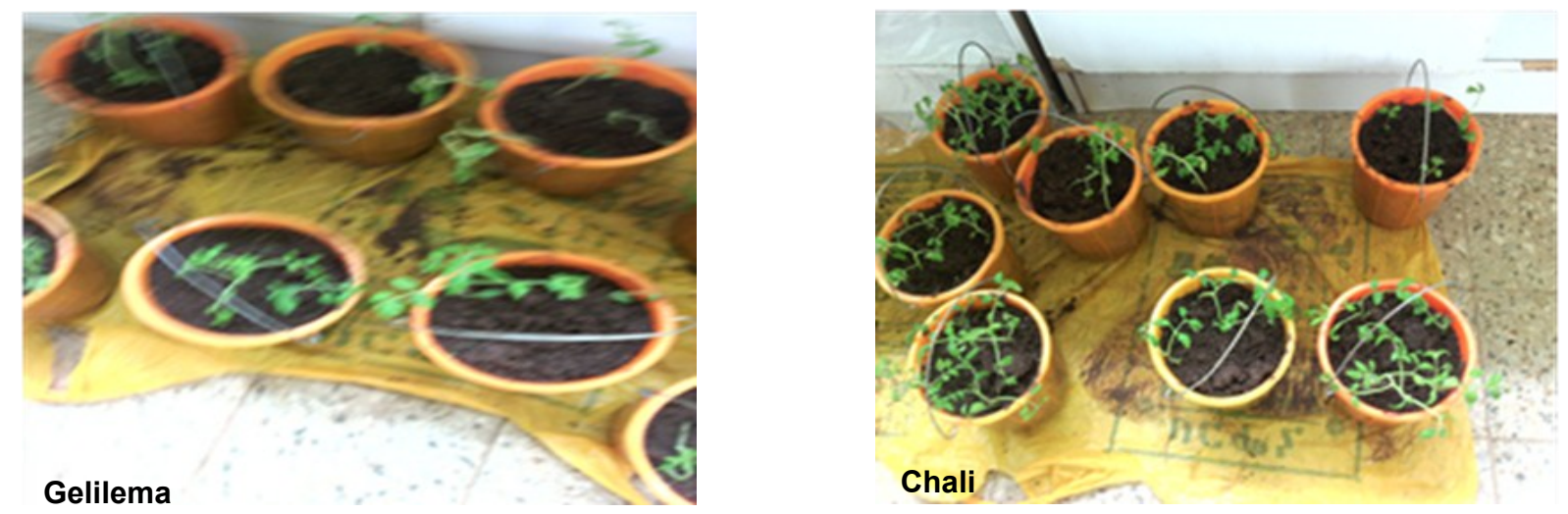

Fig. 2. Acclimatized plantlets of Gelilema and Chali varieties of tomato after 15 days in a lath house.

any exogenous plant growth regulators. This may, due to the presence of high endogenous auxin concentration in tomato plant. Likewise, Kartha et al. (1975) found that the presence of endogenous auxin in the regenerated shoots of tomato cultivar Starfire facilitates an exogenous-auxin-independent root formation and production of complete plants. The present result is contradictory to the report of (Rao et al. 2005; Dan et al., 2006). Rao et al. (2005) reported that culturing on MS medium containing auxin resulted in a large proportion of rooted micro-shoots and early rooting than cultivation on an auxin-free medium. Dan et al. (2006) also conducted an experiment using cotyledon explants derived from tomato Micro-Tom cultivar and concluded that MS medium supplemented with $1 \mathrm{mg} / \mathrm{l}$ IBA gave a good response to rooting over the control and $2 \mathrm{mg} / \mathrm{l}$.

In the case of a number of roots/explants Chali gave the highest $(14.20 \pm 0.3464)$ roots per shoot with an average root length of $10.7 \pm 0.29 \mathrm{~cm}$ on free MS medium (Table 1; Figure 1). On the same media, Gelilema resulted in $14.17 \pm 0.29$ roots/shoot having an average root length of $7.58 \pm 0.14 \mathrm{~cm}$. There was no significant difference in the number of roots per shoot in the two varieties cultured on the free MS media. A similar re- sult was obtained by Amitav (2011) who reported that tomato varieties Maple and BARI-3 produced the same number of roots on MS+0.5 IBA. But as that of our root length result, there was a significant difference in the two varieties. The minimum numbers of roots/ shoot and average root length were recorded from MS medium supplemented with $1.5 \mathrm{mg} / \mathrm{l}$ IBA in both varieties. Overall the lowest value of a number of roots/ shoot $(0.887 \pm 0.196)$ with an average root length of $1.00 \pm 0.00 \mathrm{~cm}$ was recorded from Gelilema variety on MS+1.5 mg/l IBA. On the same media, Chali produced $2.67 \pm 0.57$ numbers of roots per shoot having an average root length of $4.33 \pm 0.577 \mathrm{~cm}$.

In both of the varieties used the number of roots per shoot and root length per shoot were decreased as the IBA level increased until $1.5 \mathrm{mg} / \mathrm{l}$. This may occur due to the inhibitory effect of higher auxin concentration. Similarly, Sedaghat and Rahemil (2012) found that higher concentrations of auxin provoke ethylene production and inhibit root growth. Likewise, Sakthivel and Manigandan (2011) found that the increase in the level of IBA from $0.5 \mathrm{mg} / \mathrm{l}$ to 1.5 resulted in the decrease of both the number of roots and root length $\mathrm{mg} / \mathrm{l}$ in PKM1 tomato variety. The present result is also in conformity with Ishag et al. (2009) who found that the number of 
roots/shoot and root length of plantlets that originated from shoot tip explant of tomato cultivar Omdurman decreased as the level of IBA increased from 0 to 0.5 $\mathrm{mg} / \mathrm{l}$. On the other hand, Banu et al. (2017) said that exogenous application of auxin has been found effective in the formation of increased root number per shoot and percentage of rooted shoot compared to control plantlets in three tomato varieties namely $\mathrm{H}-3$ (BARI Hybrid-3), BH-4 (BARI Hybrid-4) collected from BARI (Bangladesh Agricultural Research Institute) and MH (Minto Hybrid). In another research, Mukta (2014) also found the contradictory result to the present who reported that when the concentration of exogeneous growth regulators particularly IAA increased, the highest number of roots (15-30) was formed but required highest day for root initiation and all the roots were short (average length 1.5-3 cm). This may due to the dependence of the cultured plants on the type of auxin used. Similarly, Bhatia (2003) found that the in vitro response of cultured tomato is dependent on the auxin type used for rooting.

In another work, Pampanna (2009) reported a contradictory number of roots per plant and shoot length to the present result by which the highest number of roots per plantlet and root length were found from MS medium supplemented with the highest level of IBA in both explants. On the control, a root number of 9.6 having a length of $1.96 \mathrm{~cm}$ in cotyledon and 9.8 with $2.16 \mathrm{~cm}$ in hypocotyl were reported by the author. Both numbers of roots and root length increased as the level of IBA increased from the control to $1 \mathrm{mg} / \mathrm{l}$ in both the explants and concluded that root length, number of roots per plantlet and nature of roots were better at $1 \mathrm{mg} / \mathrm{I} \mathrm{IBA}$.

All the values rooting $\%$, number of roots per shoot and root length in $\mathrm{cm}$ obtained from the present rooting experiment were in line with Otroshya et al. (2013) who found that all the parameters were better on MS medium free of IBA for in vitro rooting of Cerasiforme varieties of tomato. The researchers recorded $100 \%$ rooting with 15.38 numbers of roots having a root length of $16.6 \mathrm{~cm}$ on free MS medium. This may be due to the existence of sufficient endogenous level of auxin in tomato (Devi et al., 2008) in tomato. Similarly, Himabindu (2008) said that the response of a plant species to an exogenous growth regulator depends on the endogenous level of that growth regulator in that species.

Acclimatization: For acclimatization, plantlets with well-developed root and leaf were removed from rooting medium and washed thoroughly to remove adhering gel. Then transplanted into plastic pots containing a mixture of oven sterilized soil and sand at a ratio of 2:1 and covered with a white plastic to maintain high humidity and kept under washing room conditions for 7 days. Then the plastic covers were removed and transferred to lath house and placed under shade until growth was observed. After 15 days, the survival rate was recorded. 31 in vitro rooted plantlets from each variety were used for acclimatization experiment. Out of the 31 plantlets acclimatized a retrieval rate of $67.7 \%$ and $58.1 \%$ for Chali and Gelilema respectively was obtained after 15 days (Figure 2). Some plantlets failed to survive in the ex-vitro environment after transferred to lath house. This may due to the change in the environmental condition. Because, during in vitro culture, plantlets grow in closed containers under controlled humidity, light, nutrient and aseptic conditions. A contradictory result was reported by Namitha and Negi (2013) who found that survival of $70-80 \%$ from in vitro grown plantlets of tomato cultivar Arka Ahuti.

\section{Conclusion}

Rooting of in vitro propagated micro-shoots is one of the important stages of micropropagation that affects the survival rate of plantlets under ex-vitro environment. In vitro propagation is affected by a number of factors, one of them is genotype of the given explant. Thereby, it is mandatory to optimize an in vitro rooting protocol for micro-shoots obtained through micropropagation. In the present study, an efficient in vitro rooting protocol was optimized for two tomato (Gelilema and Chali) varieties. In conclusion, MS medium free of PGRs resulted in the superiority of the collected parameters for in vitro rooting of plantlets over MS medium supplied with IBA. Thus, this genotype-specific protocol could be useful for in vitro rooting of the two varieties of tomato (Gelilema and Chali) in the future. Further studies using other types and combination of PGRs are suggested. The acclimatization to the external environment using other mixtures for getting a higher rate of survival also deserves attention.

\section{ACKNOWLEDGEMENTS}

We would like to express our thanks to the Ethiopian Ministry of Education for funding the research and Jimma University College of Agriculture and Veterinary Medicine, Ethiopia for providing the required facilities of Plant Tissue culture laboratory.

\section{REFERENCES}

1. Ashakiran, K., Sivankalyani, V., Jayanthi, M., Govindasamy, V. and Girija, S. (2011). Genotype specific shoots regeneration from different explants of tomato (Solanum lycopersicum L.) using TDZ. Asian. J. Plant Science and Research. 1(2):107-113.

2. Bahurupe, J., Patil, S.C., Pawar, B.D., Chimote, V.P. and Kale, A.A., 2013. Callus induction and plantlet regeneration in tomato (S. Lycopersicum L.). J. Cell Tissue Res. 2:37653768. 
3. Banu, N.A. Islam, S., Islam, M.A. and Alam, M.K., 2017. In vitro propagation from shoot tip and nodal segment in summer tomato (L. esculentum Mill.) Plant Environ. Dev. 6(1):31-38.

4. Bhatia, P., 2003. Regeneration, micropropagation, and somatic embryogenesis in tomato (Lycopersicon esculentum Mill.). 305p. A thesis submitted for the degree of Doctor of Philosophy, School of Biological and Environmental Sciences, Central Queensland University, Queensland, Australia.

5. Cheema, D. S. and Dhaliwal, M. S., 2005. Hybrid Tomato Breeding. J. New Seeds.6:1-14.

6. Dan, Y., Yan, H., Munyikwa, T., Dong, J., Zhang, Y. and Armstrong. C.L., 2006. MicroTom-a high throughput model transformation system for functional genomics. Plant Cell Rpt. 25:432-441.

7. Datta, A., 2015. Transgenic tomato (S. lycopersicum Mill.) regeneration by comparing different transformation techniques. 135p. A Dissertation Submitted to BRAC University in Partial Fulfillments of the Requirements for the Master of Science in Biotechnology, BRAC University, Bangladesh.

8. Devi, R., Dhaliwal, M., Kaur, A. and Gosal, S., 2008. Effect of growth regulators on in vitro morphogenic response of tomato. Indian J. Biotec... 7:526-530.

9. Eyob, B., Tesfaye, H. and Dejene, H., 2014. Growth and instability in area, yield and production of tomato in Ethiopia. IJDR. 4: 2215-2218.

10.FAO STAT, 2016. Food and Agriculture Organization of the United Nations data.(http://www.fao.org/faostat/en/ \#data/QC/visualize (19/12/2017).

11. Gao, G., 2017. Growing Tomatoes in the Home Garden. Fact Sheet: Agriculture and Natural Resources. TDD, (800-589). 8292p.

12. Gerszberg, A., Hnatuszko-Konka, K., Kowalczyk, T. and Kononowicz, A.K., 2015. Tomato (S. Lycopersicum L.) in the service of biotechnology. PCT and Organ Culture. 120(3):881-902.

13.Himabindu, K.B., 2008. Standardization of Agrobacterium mediated transformation protocol in tomato (Solanum Lycopersicon I. CV. Pkm-1). (Doctoral Dissertation, Acharya Ng Ranga Agricultural University, Rajendranagar, Hyderabad.).

14. Ishag, S., Osman, M.G. and Khalafalla, M.M., 2009. Effects of growth regulators, explant and genotype on shoot regeneration in tomato $(L$. esculentum cv Omdurman). Int J Sustain Crop Prod. 4(6):7-13.

15.Izadpanah, M. and Khosh-Khui, M., 1992. Comparisons of in vitro propagation of tomato cultivars. Iran Agric. Res. 8:37-47.

16.Jehan, S. and Hassanein, A.M., 2013. Hormonal requirements trigger different organogenic pathways on tomato nodal explants. American J. Plant Sciences. 4(11):21182125.

17.Kalloo, G., 1991. Genetic improvement of tomato. Springer Berlin Heidelberg. pp. 1-9.

18.Kartha, K. K., Gamborg, O. L., Shyluk J. P., and Constabel F., 1975. Morphogenetic Investigations on in vitro Leaf Culture of Tomato (L. esculentum Mill. CV. Starfire) and high Frequency Plant Regeneration 1). Pflanzenphysiol. Bd. 77:292-301.
19.Kiran, B.U., 2007. Studies on the development of transgenic tomato (L.esculentum Mill. var Pusa Ruby) Via Agrobacterium and biolistic methods.163p. A Thesis Submitted to the Acharya N.G. Ranga Agricultural University in Partial Fulfillments of the Requirements for the Award of the Degree of Master of Science in Agricultural Biotechnology.

20.Mamidala, P. and Nanna, R.S., 2011. Effect of genotype, explant source and medium on in vitro regeneration of tomato. Inter. Genetics and Molecular Biology. 3(3):45-50.

21.Mensuali-Sodi, A., Panizza, M. and Tognoni, F., 1995. Endogenous ethylene requirement for adventitious root induction and growth in tomato cotyledons and lavand in micro-cuttings in vitro. Plant Growth Regulation. 17(3):205 -212 .

22. Moghaieb, R.E., Saneoka, H. and Fujita, K., 1999. Plant regeneration from hypocotyl and cotyledon explant of tomato $(L$. esculentum Mill.). Soil science and plant nutrition. 45(3):639-646.

23.Mohamed, A.A.N., Ismail, M.R. and Rahman, M.H., 2010. In vitro response from cotyledon and hypocotyls explants in tomato by inducing 6-benzyl-aminopurine. African J. Biotec.. 9(30):4802-4807.

24.Mukta, F.A., 2014. Study of in vitro regeneration and transformation parameters for the development of transgenic Tomato (S. Lycopersicon L.). 91p. A Dissertation Submitted To BRAC University in Partial Fulfilment of the Requirements for the Degree of Master of Science in Biotechnology.

25.Namitha, K.K. and Negi, P.S., 2013. Morphogenetic Potential of Tomato ( $L$. esculentum Mill.) CV. Arka Ahuti to Plant Growth Regulators. Notulae Scientia Biologicae. 5 (2):220-225.

26.Opeña, R. T., Chen, J. T., Kalb, T. and Hanson, P., 2001. Hybrid seed production in tomato. AVRDC International Cooperators Guide Publication. pp. 1-4.

27.Osman, M.G., Elhadi, E.A. and Khalafalla, M.M., 2009. Effects of growth regulators, explant and genotype on shoot regeneration in tomato ( $L$. esculentum Mill, C. V. Omdurman) Int. J. Sustain. Crop Prod. 4(6):7-13.

28. Otroshya, M., Khalilia, Z., Ebrahimi, M A., Nekoui, M. K. and Moradi K., 20013. Effect of growth regulators and explant on plant regeneration of Solanum lycopersicum L. var. cerasiforme. Russian Agricultural Sciences. 39(3):226-235.

29.Pampanna, Y., 2009. Studies on in vitro regeneration and transformation of tomato ( $L$. esculentum $L$.) CV. VYBHAV with chitinase gene. 284p. Doctoral dissertation, University of Agricultural Sciences Gkvk, Bengaluru.

30.Rahman, M.M. and Kaul, K., 1989. Differentiation of sodium chloride tolerant cell lines of tomato ( $L$. esculentum Mill.) cv. Jet Star. J. Plant Physiol. 133:710-712.

31. Rao, K.V., Kiranmayee, K., Pavan, U., Jaya Sree, T., Rao, A.V. and Sadanandam, A., 2005. Induction of multiple shoots from leaf segments, in vitro-flowering and fruiting of a dwarf tomato ( $L$. esculentum). J. Plant Physiol. 162:959-962.

32.Sakthivel, S. and Manigandan, V., 2011. Tissue culture studies in tomato (L. esculantum, PKM1) from cotyledonary leaf explants. Inter $j$. Chemical and pharmaceutical sciences. 2(3):22-25.

33.Sedaghat S. and Rahemi, M., 2012. Root Regeneration in 
Baye, E. et al. / J. Appl. \& Nat. Sci. 12(3): 365 - 371 (2020)

Pistachio Rootstock is affected by Auxin and Polyamines. Journal of Nuts. 3(3):55-61.

34.Sherkar, H.D.and Chavan, A.M., 2014. Studies on callus induction and shoot regeneration in tomato. Sci Res Rep. 1:89-93.

35.Shtereva, L.A., Zagorska, N.A., Dimitrov, BD., Kruleva, M.M. and Oanh, H.K., 1998. Induced androgenesis in tomato (Lycopersicon esculentum Mill.). II. Factors affecting the induction of androgenesis. Plant Cell Rep. 18:312-317.

36.Singh, N., Kumar, A. and Garg, G., 2006. Genotype dependent influence of phytohormones combination and subculturing on micropropagation of sugarcane varieties. Indian J. Biot. 5(1):99-106.

37.Sudha, M., Gajanana, T.M. and Sreenivasa Murthy, D., 2006. Economic impact of commercial hybrid seed production in vegetables on farm income, employment and farm welfare-a case of tomato and okra in Karnataka. Agricultural Economics Research Review. 19:251-268.

38.Wijbrandi, J., Vos, J.G.M. and Koornneef, M., 1988. Transfer of regeneration capacity from Lycopersicon peruvianum to $L$. esculentum by protoplast fusion. Plant Cell Tiss. Org. Cult. 12:193-196. 